\title{
Voting Advice Applications and Electoral Participation: A Multi-Method Study
}

\section{Diego Garzia, Alexander H. Trechsel \& Andrea De Angelis}

To cite this article: Diego Garzia, Alexander H. Trechsel \& Andrea De Angelis (2017) Voting Advice Applications and Electoral Participation: A Multi-Method Study, Political Communication, 34:3, 424-443, DOI: 10.1080/10584609.2016.1267053

To link to this article: https://doi.org/10.1080/10584609.2016.1267053

View supplementary material $[\pi$

Published online: 15 Feb 2017.

Submit your article to this journal $\widetilde{ }$

WII Article views: 1083

Q View related articles $\sqsubset$

View Crossmark data \lceil

Citing articles: 13 View citing articles $\sqsubset$ 


\title{
Voting Advice Applications and Electoral Participation: A Multi-Method Study
}

\author{
DIEGO GARZIA, ALEXANDER H. TRECHSEL, \\ and ANDREA DE ANGELIS
}

\begin{abstract}
Voting Advice Applications (VAAs) help users casting a vote by offering an explicit ranking of viable options. The wide amount of readily available information provided by VAAs to users has been shown to contribute to reducing the transactional costs involved in gathering relevant political information. Available evidence also supports the idea that VAA users are more likely to cast a ballot in elections as a result. The extent to which electoral participation is caused by using a VAA, however, remains unclear. Against this background, we reassess the mobilizing effect of VAAs by means of a multi-method approach. Our cross-sectional analysis of 12 national election study data sets provides further support to the idea that VAA usage increases users' chances of casting a ballot in elections as compared to non-users. This conclusion is strengthened by the results of a randomized field experiment conducted in the context of the 2013 Italian parliamentary election.
\end{abstract}

Keywords ICTs and political behavior, tailor-made information, turnout, Web 2.0

\section{Introduction}

The advent of the World Wide Web has profoundly altered the way political information is produced and digested by the wider public at election time. Over the past two decades, the multiple links between Internet-based information and communication technologies (ICTs) and the political process were put under scrutiny by social and political scientists. The available literature has generated relatively ample evidence that in Western democracies the emergence of the Internet resulted in a significant change within political behavior (for a review, see Chadwick \& Howard, 2009). Research has focused on its possible impact on political engagement and participation, either directly (e.g., encouraging users to participate) or indirectly (e.g., providing them with the necessary information to do so) (Norris, 2000). And indeed, Web-based political information has been shown to bear a positive impact on broadly defined patterns of political engagement (for a review, see Boulianne, 2009) as well as more specific patterns of electoral participation (Bond et al., 2012; Tolbert \& McNeal, 2003) - this being especially the case with the younger generation (Hirzalla, Van Zoonen, \& De Ridder, 2010).

Diego Garzia is Senior Research Fellow (SNF Ambizione) at the University of Lucerne. Alexander H. Trechsel is Professor of Political Science and Political Communication at the University of Lucerne. Andrea De Angelis is Researcher and Lecturer at the University of Lucerne.

Color versions of one or more of the figures in the article can be found online at www. tandfonline.com/UPCP.

Address correspondence to Dr. Diego Garzia, University of Lucerne, Department of Political Science, Frohburgstrasse 3, Lucerne 6002. Switzerland. E-mail: diego.garzia@unilu.ch 
In the past decade, a new type of online tool has mushroomed in European democracies and beyond. Voting Advice Applications (hereafter: VAAs) help users casting a vote by comparing their policy preferences on major issues with the programmatic stances of political parties on such issues (for an overview of VAAs in comparative perspective, see Marschall \& Garzia, 2014). VAA respondents fill in a questionnaire with their position on a wide range of concrete policy statements. After comparing the user's profile with that of each party/candidate, the VAA produces its "advice," usually in the form of a rank-ordered list, at the top of which stands the party/candidate closest to the user's policy preferences. Whereas the advice provided by the VAA is to be considered as a form of political communication, it must be also noted that it differs considerably from most of the campaign messages that citizens traditionally receive. Like traditional media, they relay information about parties' and candidates' positions to voters. Unlike other sources, however, they provide customized political information. VAAs offer an explicit ranking of viable options with an implication that this ranking is tailored according to the user's political opinions. In other words, VAAs reveal to the user the structure of the political competition in light of her own preferences. The ability of VAAs to reduce the costs of information at election time is one of the keys to understand their growing success among voters (Alvarez, Levin, Trechsel, \& Vassil, 2014). Nowadays, the existence of at least one VAA has been witnessed in virtually all Western democracies. In countries like Belgium, Germany, Switzerland, and the Netherlands, the proportion of eligible voters resorting to VAAs at election time ranges between $10 \%$ and $40 \%$ (Marschall, 2014). In some Scandinavian countries, VAAs are mentioned as the primary source of political information during the campaign by a relative majority of voters, outnumbering traditional media such as newspaper and television (Ruusuvirta, 2010).

The massive spread of VAAs across countries and users and their increasing relevance in the electoral process have resulted in a fast-growing number of academic publications devoted to the topic (for a review, see Garzia, Trechsel, Vassil \& Dinas 2014). A significant stream within this literature shares a common interest in political behavior and, in particular, in the ways in which VAAs can affect voters' patterns of electoral participation. Available evidence supports the idea that VAA users are better informed and hence more likely to cast a ballot in elections as compared to non-users (Schultze, 2014). The extent to which electoral participation is caused by using a VAA, however, remains unclear. Exclusive reliance on case studies, data limitations, and methodological shortcomings plagued in one way or another virtually all previous studies. Against this background, we propose to reassess the electoral impact of VAAs, focusing on their actual mobilizing potential through the following research question: Do VAAs increase the likelihood of their users to cast a ballot in elections? We begin by sketching our theoretical framework. Then, we provide a critical review of the available works on the topic. After having outlined the uniqueness of our twofold methodological approach, we present the results of our empirical analyses, focusing in turn on cross-sectional data and experimental evidence. The final section discusses the results as well as their major normative implications.

\section{Theoretical Framework}

The focus of our analyses lies in the effects of VAAs on individual-level turnout. ${ }^{1}$ Is there a link between being exposed to VAA-generated information and the individual's decision to go to the polls? In his seminal contribution, Downs (1957) postulated that the act of voting had a certain cost (e.g., the necessity of informing oneself, going to the polls, and 
so on). For rational voters, therefore, the benefit from voting had to outweigh the costs for taking part in the collective decision at the polls. Ever since, the study of individual-level turnout has either further developed this rational-choice approach or led to the development of new models of electoral participation. Entire schools have emerged over time, complementing and contrasting the Downsian voter paradox. In a recent review article, Smets and van Ham (2013) propose a most valuable meta-analysis of these competing theoretical perspectives and their application in empirical studies, identifying six different models of voter turnout: the resource model, the mobilization model, the socialization model, the rational choice model, the psychological model, and the political institutional model. The authors find that only a small number of variables is consistently linked to voter turnout across the vast majority of studies, eventually helping us to develop a "core model" of voting. It is not the aim of this contribution to find such a core model, but to investigate the effect of an ever more popular form of political information gathering on turnout: VAA exposure.

Exposure to information generated by a VAA during campaigns can have an effect on some of the key variables that are part of any of the six models analyzed by Smets and van Ham. For instance, information acquired through the use of a VAA can stimulate interest (psychological model) and political discussion (socialization model), it can either resonate more effectively among better-educated citizens or compensate for lower levels of education (resource model), it belongs to the broader family of media exposure indicators (mobilization model), it can reduce the cost of information gathering and processing (rational choice model) and it may even lead to a better understanding of partisan conflict through the closeness of parties and their electoral importance (political institutional model). However, we believe that it is the intersection among the resource model, the rational choice model, and the psychological model where we find the possibly best-suited theoretical harbor for this new form of self-gathered campaign information.

The resource model postulates that political resources, such as information and knowledge, are a key precondition for participation (Verba, Schlozman, \& Brady, 1995). With more information, citizens are better able to make sense of their own position relative to the electoral supply and thus more likely to cast their ballot in elections. Available studies confirm that higher levels of political information increase the likelihood of voting (Delli Carpini \& Keeter, 1996; Lassen, 2005; Palfrey \& Poole, 1987). VAA exposure clearly adds to the information available to individual voters and should therefore be positively linked to the likelihood of voting.

Actively gathering information has, of course, a certain cost. From the rational choice model we know that the individual-level probability to cast a vote is inversely proportional to the effort required to gather information. The costs that are involved in the process of becoming sufficiently informed are, for instance, linked to the procurement (i.e., the gathering) of the relevant data. Furthermore, the analysis of the information gathered as well as the evaluation of the latter, relating it to specific goals, bears certain costs (Carmines \& Huckfeldt, 1996, p. 245). With several issues at stake and a multitude of parties and/or candidates running for office, the task of gathering information may augment the cost of voting up to a point that overcomes benefits, thus possibly keeping away citizens from the ballots. In the low-information rationality framework, voters are expected to minimize this effort by relying on whatever "free" or inexpensive information can be picked up (Popkin, 1991). In this sense, the wide amount of readily available information about politics and political parties provided by the VAA contributes to reducing the transactional costs involved in gathering relevant political information and increasing the likelihood of voting in turn. 
Finally, a key component of the psychological model of voter turnout are "cognitive characteristics such as political interest, political knowledge, or cognitive ability to personal preferences associated with expressive voting such as party identification and ideology" (Smets \& van Ham, 2013, p. 11). Available studies of VAA effects on users' political knowledge confirm the idea that VAAs improve users' knowledge about political matters during the campaign. Ladner (2012) reports more than four smartvote users out of five indicating that using the VAA improved their knowledge of the 2011 Swiss election. Kamoen and colleagues' (2015) analysis of the 2012 Dutch parliamentary election provides evidence that VAA usage increased users' factual knowledge of political parties and party standpoints. Similar figures are reported by Schultze (2014) for the case of Germany. These knowledge effects appear larger for young users (Ladner, Fivaz, \& Nadig, 2009) as well as among those who consider VAAs to be a "serious" advice instrument (Alvarez, Levin, Trechsel, \& Vassil 2014; Kamoen et al., 2015). Other studies have, in addition, found that the link between VAA exposure and mobilization at the polls can be conditioned by the output of the VAA. Higher levels of overlap of one's political preferences with the political offer may generate a positive effect on individual-level turnout (Dinas, Trechsel, \& Vassil, 2014).

In this contribution we refrain from making any conclusive claims about the supremacy of one model of voter turnout over the other. Also, we are not able to distinguish an individual mechanism leading to potential effects of VAA exposure on turnout. But we are able to measure whether these effects can be detected in the first place. On the basis of the idea that VAAs lead users to the acquisition of more information, to the reduction of the costs of information gathering, and to the stimulation of political interests and knowledge, the remainder of this article tests the hypothesis that VAA exposure leads to a higher probability of casting a vote.

Future work will have to develop research designs that explicitly distinguish between the different mechanisms at work. For the time being, and as a first step, we must limit ourselves to the sheer detection of the link between exposure and turnout. Based on our knowledge of the existing theories of turnout, we expand the theoretical framework to include VAA exposure as a potential explanation for electoral participation. Also, never before has the link between VAA exposure and voting been so thoroughly analyzed, relying on both observational and experimental studies. With this contribution we therefore aim at further developing the literature on individual-level turnout explanations by adding a thorough test of our main hypothesis.

\section{Cross-sectional Evidence: Review and Analysis}

The first studies investigating the impact of VAAs on electoral participation were conducted by Marschall and his team on the case of the German Wahl-O-Mat. In both the 2004 and the 2009 German federal elections, more than one user out of 10 declared to feel more motivated to turnout because of having used that VAA (Marschall, 2005; Marschall \& Schmidt, 2010). In the same years, another research group, led by Ladner, began analyzing the electoral impact of the Swiss VAA smartvote. Their early analysis of the 2007 federal election found about $40 \%$ of respondents declaring that using the VAA will bear a decisive or at least slight influence on their decision to go to the polls (Ladner \& Pianzola, 2010). On the basis of these data, Fivaz and Nadig (2010) concluded that the overall turnout in that election could have been about 5\% lower had the smartvote platform not made available to Swiss voters. 
A critical issue with the aforementioned studies lies with their exclusive reliance on opt-in surveys administered to users right after having been exposed to the VAA. In other words, the influence exerted by the VAA on users is measured through subjective estimates of (future) impact and only among those who are willing to complete the optin survey. Apart from being subject to a heavy self-selection bias, these type of data do not even ensure that subjective assessments will match with actual changes in terms of preferences and behavior. Indeed, Walgrave, van Aelst, and Nuytemans (2008) found that the reported intention of changing behavior as a result of having used a VAA is not always (nor often) matched with actual changes in voting behavior at election time.

In order to address this critical issue, VAA scholars have turned to representative survey data. Marschall and Schultze (2012) took advantage of a pre-electoral wave of the German Longitudinal Election Study (GLES) and found a 6\% increase in the probability to cast a ballot among VAA users as compared to non-users. However, their study suffers a low external validity because the data set employed consists of a non-random sample of the German online population. Moreover, the dependent variable is measured before the election, so one cannot be sure whether turnout intentions get actually converted into electoral participation.

To overcome these limitations, a growing number of studies have resorted to national election study data. Working with nationally representative samples increases substantially the external validity of the findings. At the same time, the structure of post-election surveys allows for factual measures of VAA usage (rather than subjective assessments of impact) and actual voting behavior. Gemenis and Rosema's (2014)analysis of 2006 Dutch Parliamentary Election Study (DPES) data estimates, by means of simulation, that the presence of VAAs was responsible for $4.4 \%$ of the reported turnout in that election. Another analysis by Dinas, Trechsel, and Vassil (2014) on European Election Study (EES) data shows that even after controlling for a wide set of socio-structural, attitudinal, and behavioral variables, the individual-level probability to cast a vote in the European Parliament election of 2009 was 14 percentage points higher for VAA users as compared to non-users. This inventory of studies, by and large confirming the hypothesized positive association between VAA usage and electoral mobilization, highlights nonetheless commonalities in terms of their exclusive reliance on case studies. To put the mobilization hypothesis to a more demanding — albeit still correlational — test, the analysis that follows provides a comparative reassessment of the effect of VAAs on users' patterns of electoral participation across countries and time. To this aim, we resort to the growing amount of national election studies asking voters whether they used a VAA during the campaign. The present analysis expands on the number of elections included in Garzia, De Angelis, and Pianzola's (2014) study, and employs 11 data sets from four different European countries: Finland (2003, 2007, 2011), Germany (2009, 2013), the Netherlands (2003, 2006, 2010, 2012), and Switzerland (2007, 2011). We also analyze the European Election of 2009, since that year's ESS included a question on VAA usage.

The dependent variable of the analysis is a dichotomous variable indicating whether respondents did take advantage of their right to vote in the election under analysis. Another dichotomous variable measures whether respondents used one (or more than one) VAA during the campaign. One point of concern relates to the differences in questionnaire design and wording across the various national studies. In this respect, the "best" measures are provided by the Dutch and the Swiss studies, in which the whole sample is asked directly about VAA usage during the campaign. ${ }^{2}$ More complicated are the cases of Germany and Finland. In the former case, the VAA-usage question has been administered only to a subsample of respondents - namely, all those who reported to "have 
used (at least) once a week the Internet to inform themselves about political parties during the federal election campaign." We decided to code as non-users all those who declare to have never used the Internet to gather political information during the campaign. Admittedly, this coding strategy may fail to recognize occasional Internet users that took the VAA test nonetheless. Through potential underestimation of the actual number of users in the sample, this conservative strategy carries - if any - the risk of downsizing the actual effect of VAA usage on participation in our models. With respect to Finland, the national election surveys feature no direct question at all. We thus decided to resort to an indirect measure based on how much did respondents "follow the election campaign on candidate selectors on the Internet." "3 Underestimation of VAA usage (and hence its effect on electoral participation) is even more likely in this case, as not "following" the campaign through VAAs does not exclude in any way the possibility for citizens to have used a VAA. Table 1 presents the proportion of study respondents that declared to have used a VAA during the campaign in each data set.VAA usage appears, unsurprisingly, mostly spread in Finland and the Netherlands - that is, the two countries in which VAAs have appeared first. There, more than one-third of respondents declare to have used at least one VAA during the campaign. In Germany and Switzerland, this proportion amounts to about $10 \%$. Interestingly, an unambiguous upward trend in the proportion of VAA users across time can be observed in each of the countries under analysis.

A comparison of turnout rates across users and non-users in each data set is also presented in Table $1^{4}$ The bivariate analysis confirms that VAA users are systematically more likely to cast a vote in elections as compared to non-users. The statistical association between these two variables is indeed highly significant and signed as expected in each data set, and so are the various $x^{2}$ tests.

As the major purpose of the present analysis is testing to what extent electoral mobilization can be correctly attributed to the act of having used a VAA, we also need to control for a number of alternative explanations of electoral participation within a multivariate setting. Given the relatively low number of countries and elections under analysis, we abstract from contextual (i.e., socio-structural and institutional) explanations and focus on individual-level determinants. Drawing on the meta-analysis by Smets and van Ham (2013), our analysis includes statistical controls connected to individuals' sociodemographic profile (age, age-squared, gender, and educational attainment), belonging to intermediary associations (religiousness), and political attitudes (strength of party identification, self-placement on the left-right scale, interest in political matters, and sense of satisfaction toward democracy; detailed variable coding is provided in Appendix A). We also include a variable tapping whether respondents did cast a vote in the previous election in order to control for the effect of voting habits. As the decision to turn out in the previous election may have been due to at least some extent by VAA usage (something we unfortunately cannot control for due to the cross-sectional nature of the data at hand), the inclusion of this latter control serves also as a means to consider our results as a relatively conservative estimate of the impact of VAA usage on participation. Given the dichotomous nature of the dependent variable, logistic regression has been preferred to ordinary least squares (OLS) estimation.

Table 2 presents the results of our logistic regression analyses, which provide relatively strong confirmation of our research hypothesis.Indeed, the coefficient for the VAAusage variable is systematically related in a statistically significant way to the dependent variable, while its positive sign witnesses of their positive association (i.e., being a VAA user increases the likelihood that the respondent will take part in the election under analysis). 


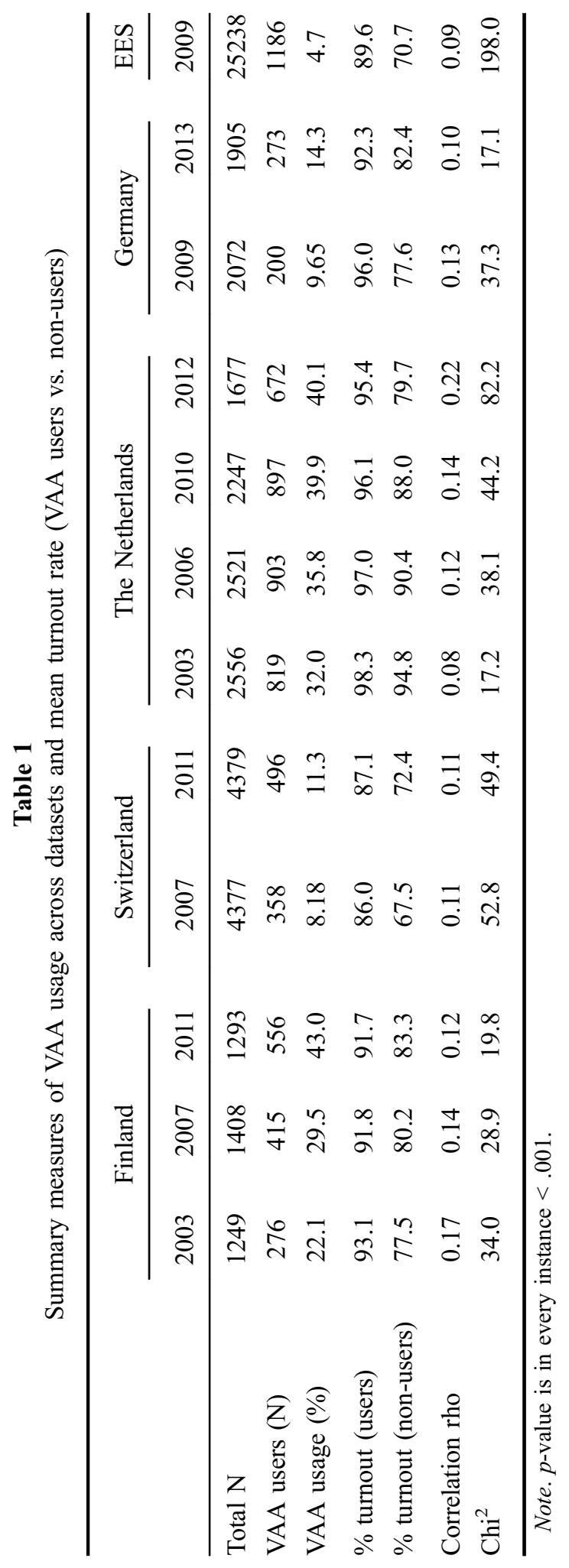




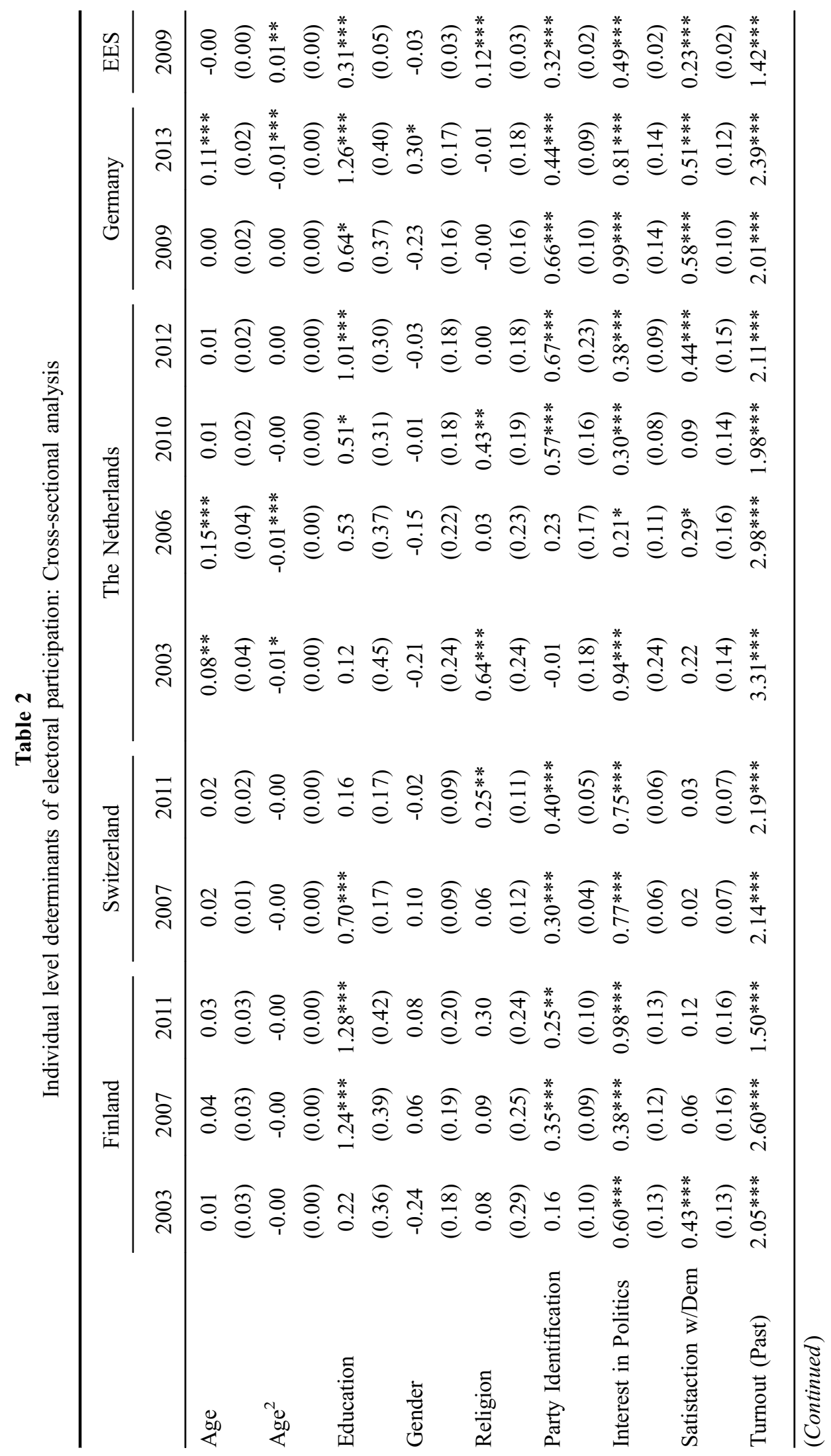









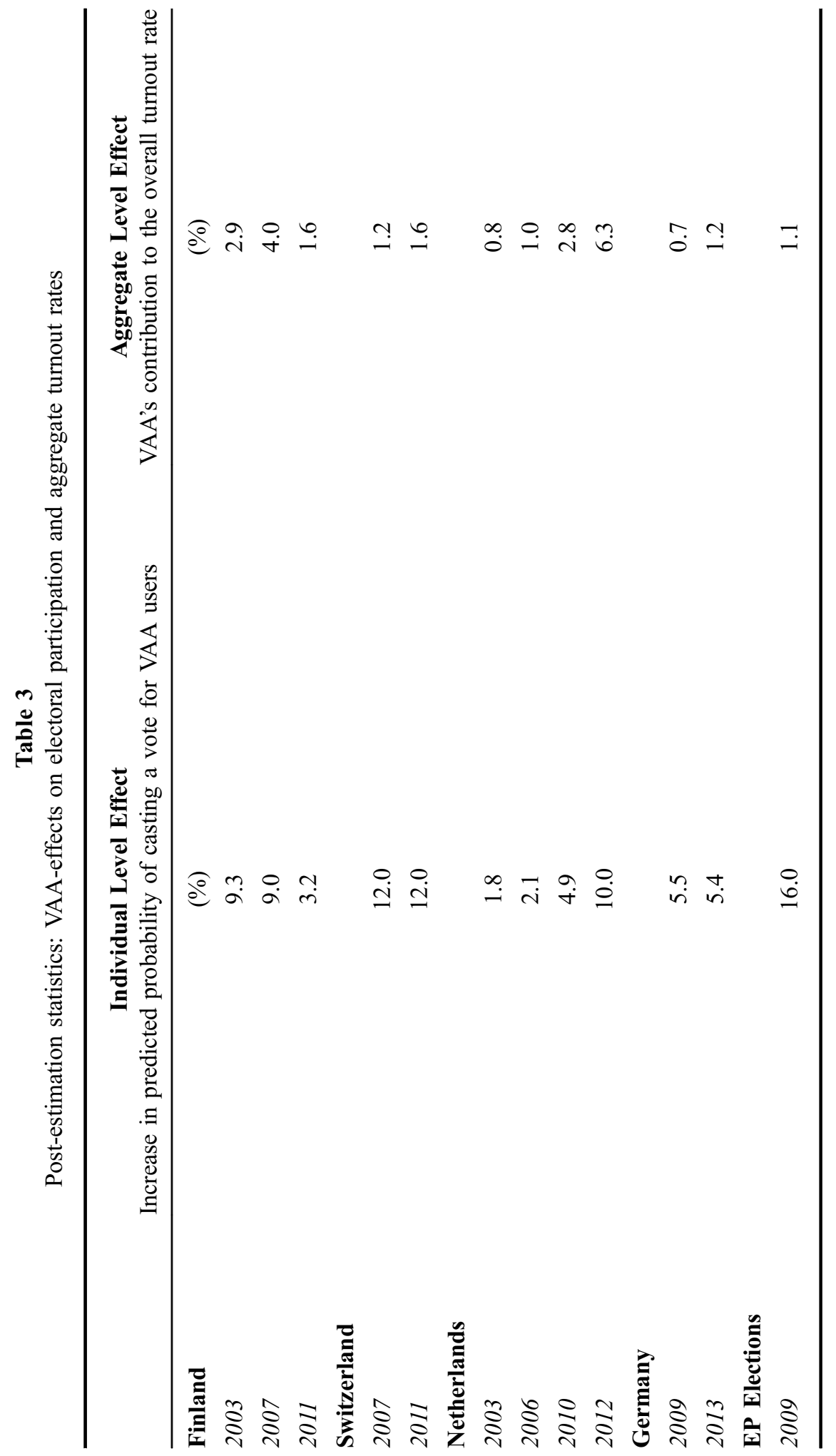




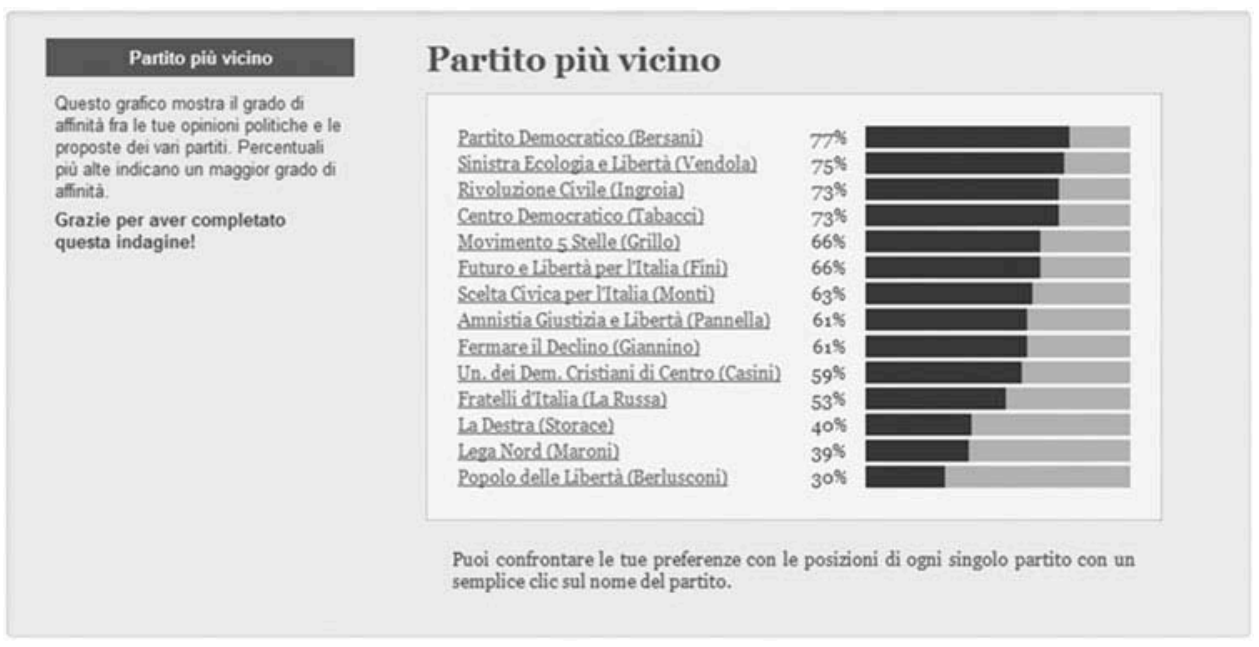

Figure 1. The VAA output: Rank-order list of parties based on their proximity to respondents.

To test the robustness of our findings, we performed a number of additional tests. First, we estimated a set of likelihood ratio tests comparing for each election the constrained model that excludes an effect of VAA usage with the unconstrained one considering it in the same subsample of voters. In every single case we were led to reject the hypothesis that VAA usage can be excluded from the empirical models of turnout. Second, we ruled out the possibility that the positive association between VAA use and electoral behavior is actually driven by relatively small categories of outliers and/or influential observations. Finally, we tackled the issue of non-random assignment of VAA usage across election study respondents through Coarsened Exact Matching (CEM) techniques. Once again, the results highlight only minimal differences as compared to the estimates provided by our logistic regressions. Detailed estimation procedure for all robustness tests is provided in Appendix B.

When it comes to the size of the statistical association, we refrain from interpreting the magnitude of the logistic regression coefficients, given that the variance of the underlying latent variable in the logit function is not identified and it is thus likely to differ across models. Instead, we rely on post-estimation statistics. In Table 3 (left column), we present the increase in the individual-level probability of casting a vote in the election under analysis moving from a value of "0" (i.e., the respondent did not use a VAA during the campaign) to a value of "1" (i.e., the respondent did use at least one VAA during the campaign) of our key independent variable, with all other variables in the model set at sample mean.

According to our estimates, VAA usage exerted its strongest impact during the 2009 EP election ( $16 \%$ increase in the predicted probability of casting a vote for VAA users). Rather strong effects can also be witnessed in the cases of Switzerland and Finland (around 10\%). To grasp a better picture of the overall impact of VAAs on turnout rates, Table 3 (right column) also reports estimates of their aggregate-level effect, stemming from a combination of individual-level effects and the actual spread of VAA usage across respondents. For each of the elections under analysis, we estimated via logit simulation how the proportion of voters in the sample would have decreased had no one used a VAA during the campaign. Although admittedly lower than individual-level figures, aggregate estimates highlight nonetheless the significant contribution of VAA usage to election turnout rates, with values ranging between $0.7 \%$ in the German federal election of 2009 
to $6.3 \%$ in the Dutch parliamentary election of 2012 . It is worth noting that, with the only exception of Finland, this figure reports a monotonic increase across time in all other countries under analysis.

\section{Experimental Evidence: Review and Analysis}

Notwithstanding the methodological advances allowing better control of respondents' data in a context plagued by self-selection into the treatment (i.e., using the VAA), it is evident that the ideal scenario for a causal assessment of VAA effects on users' patterns of electoral mobilization is the random assignment of the treatment in a proper experimental setting. In line with the view offered by Angrist and Phischke (2009), a small number of studies of VAA effects have indeed attempted to provide causal explanations within the framework of experiments. Vassil's (2012) analysis of the 2009 Estonian election to the European Parliament finds very weak, positive effects of VAA exposure on participation. As his study population consists exclusively of university students, however, the findings are of limited external validity. A similar problem afflicts the study by Mahéo (2014), who administered her "treatment" only to a subsample of voters in a low-income voter neighborhood in Montreal during the 2014 Quebec provincial election campaign.

Pianzola (2014) offers an experimental analysis of VAA effects involving a nationally representative sample of Swiss voters in the context of the federal elections of 2011. Unfortunately, this study suffers from a very low "first stage" due to the problem of twosided non-compliance. If access to a VAA is open to the public (as was the case with the Swiss VAA smartvote employed in the study), one cannot exclude the possibility that subjects in the

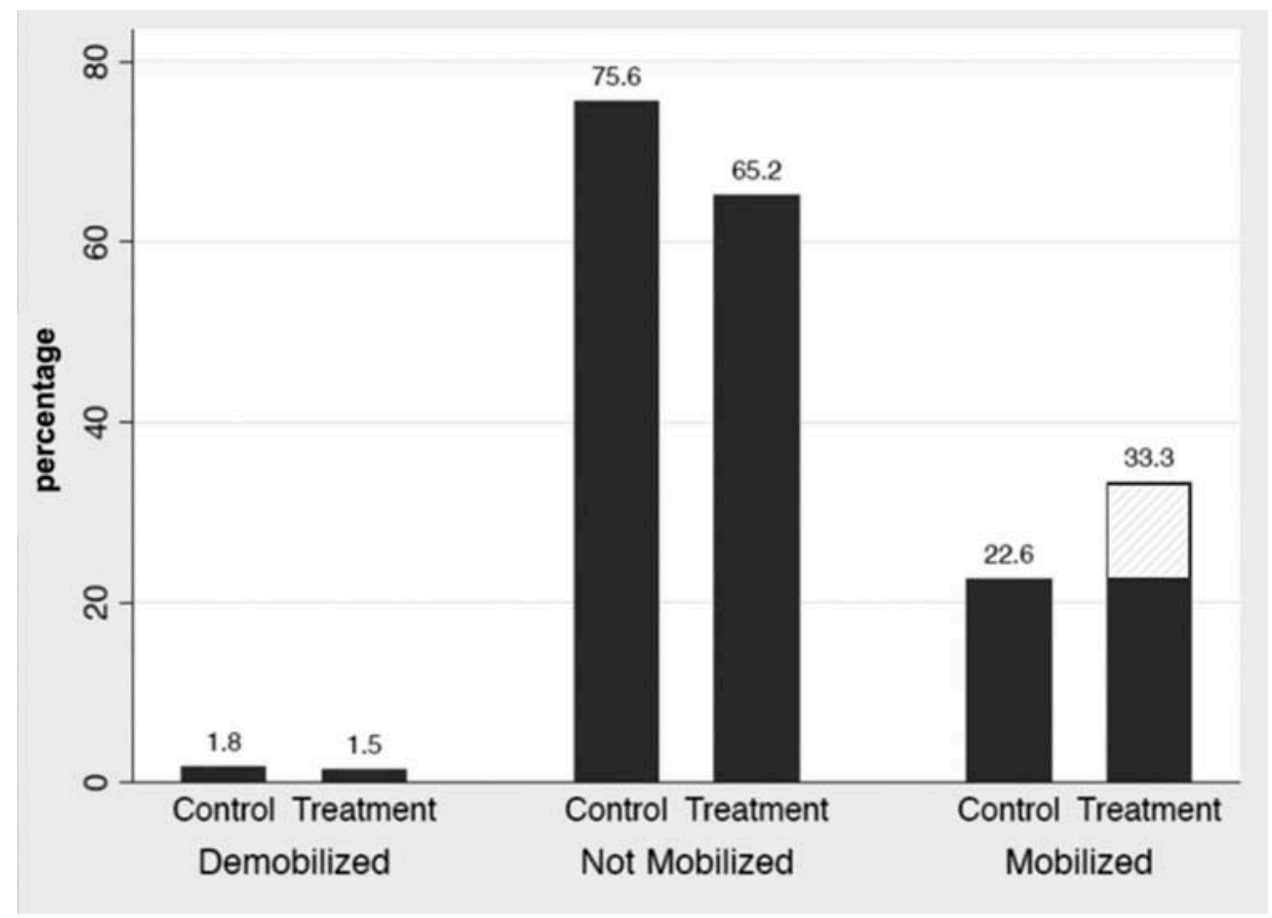

Figure 2. Patterns of across-campaign mobilization: Treatment versus control group. Note: t-value $=3.41, p<.001$. 


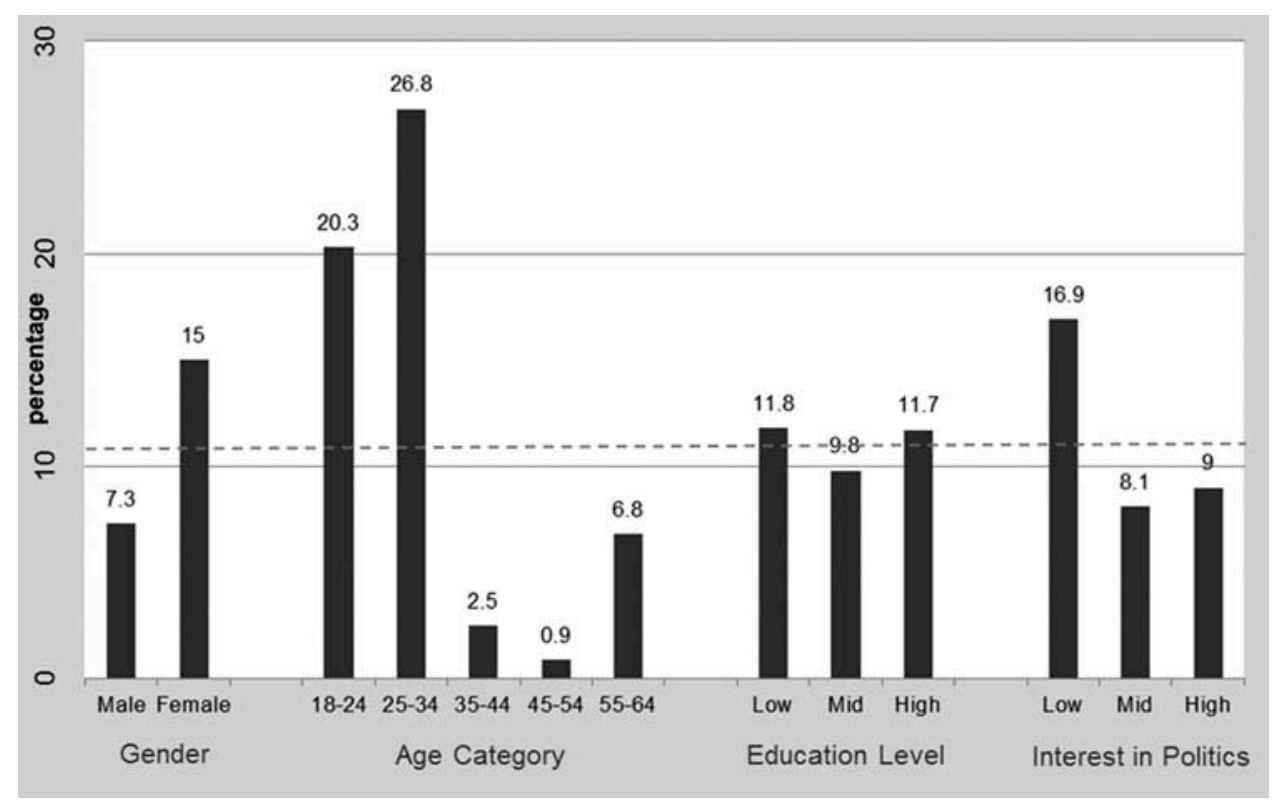

Figure 3. Subgroup analysis (treatment group only).

Note: Figure entries represent the independent effect of the treatment on mobilization. Dotted red line is mean effect across the treatment group (10.7\%).

control group could take the treatment independently from the experiment. Indeed, more than $70 \%$ of participants in the control group reported to have used smartvote. The same troubling issue - although in reduced magnitude - is to be found in the experimental design employed by Enyedi (2015) in his analysis of the 2010 Hungarian parliamentary election.

To overcome all the limitations stemming from the existing studies, we have set up an experiment in the context of the most recent parliamentary election held in Italy, on February 24, 2013. This election provides a particularly interesting setting for testing our mobilization hypothesis. For the first time in the history of Italian parliamentary elections, turnout fell below $80 \%$ - the actual figure being $75.2 \%$. Although in line with the general trend of declining turnout rates across established democracies, the magnitude of decline in the 2013 election (i.e., minus 5.3 percentage point as compared to 2008) was more marked than one could expect based on the past 20 years' trendline. Possible explanations included the growing disaffection toward politics on behalf of Italian voters, the weakening ability of traditional agents to politically mobilize the electorate (e.g., religious organizations, trade unions, political parties), and the declining trust in "newer" sources of mobilization such as political leaders, whose image capital reached an all-time low in that election (Barisione, Catellani, \& Garzia, 2013). Against this background, there is room to believe that the provision of relevant, easily accessible political information may ignite a cognitive-based pattern of (re)mobilization. The Italian case can also be considered an ideal "laboratory" for the assessment of VAA effects in the context of realworld elections. According to the comprehensive inventory of VAAs in Europe by Marschall (2014, p. 96), no actual VAA was indeed made available to Italian voters during the 2013 election campaign. Methodological concerns with respect to the problem of twosided noncompliance are further minimized by our decision to resort to a "mock" VAA platform. Through an invited accessibility design, the experimental VAA platform was in 
fact accessible only to the respondents in the treatment group. In this way, we were able to overcome the main shortcoming inherent to the existing studies without the need to indulge in the unpractical (as well as unethical) exercise of denying a group of citizens access to a VAA while forcing others to use it.

The issue statements at the core of our mock VAA platform were based on a set of most salient issues of the campaign. The final selection of 30 statements was guided by the aim of maximizing variation across parties (i.e., we excluded all those questions unable to discriminate across parties' positions) as well as comprehensiveness in terms of policy domains. The positioning of parties on the various statements was achieved on the basis of a hierarchy of available data sources. Our main source of information was the party manifestos. When information about specific issues was not available in party manifestos, we resorted to party websites' content and declarations of party leaders. If none of these sources proved useful, we made use of previous expert positioning endeavors conducted on the Italian case (i.e., ITANES Expert Survey 2011). All parties already represented in Parliament, as well as those with a reasonable chance to attain representation in the 2013 legislature, were coded by the research team, for a total of 14 parties included in the VAA. ${ }^{5}$ The experimental VAA platform invited respondents to offer their reaction to the 30 issue statements with one of five responses, ranging from "completely agree" to "completely disagree" plus a "no opinion" option. The algorithm for matching the preferences of the user with the party positions was based on the city-block method. ${ }^{6}$ The outcome visualization consisted in a simple match-list, at the top of which stands the party closest to the respondent's set of policy preferences (see Figure 1).

The experiment was embedded in a multi-wave CAWI panel of the Italian National Election Study (ITANES). The panel design of the study was especially useful for the purposes of the experiment as it allowed not only to measure the outcomes of interest after the election, but also to measure baseline attitudes and behavior before participants' exposure to the treatment. ${ }^{7}$ The experimental protocol consisted of three stages:

1. Pre-treatment measurement: The pre-treatment measurement was carried out on the entire sample population $(N=908)$ on January 2013. The survey included items about respondents' baseline political attitudes and behavior (i.e., willingness to participate in the forthcoming national election and voting intention).

2. Randomization and treatment assignment: The sample has been randomly split into halves $(N=454){ }^{8}$ Only the treatment group received (on February 15, 2013) an invitation to take part in the experiment. Upon acceptance, respondents were redirected to our server and given the opportunity to go through the VAA. The response rate was a noteworthy $95.6 \%(N=434)$. Users' perceptions of the usefulness of the VAA were widely positive: $35 \%$ of the respondents rated it "very useful" and $45 \%$ "fairly useful."

3. Post-treatment measurement: The post-treatment measurement was carried out in late February/early March 2013. This involved all respondents in the control group as well as all those respondents in the treatment group who accepted to take part in the experiment (total $N=888$ ). The key attitudinal questions remained identical from those in the previous wave in order to achieve full comparability. As to turnout, the voting intention measure was replaced with its behavior-recall counterpart (i.e., "did you vote in the last national election?").

In this article we focus our analysis on the potential effects of VAA exposure on across-campaign patterns of electoral participation. In other words, our dependent variable 
is mobilization - that is, the difference in the intention to participate in the forthcoming national election as measured in the pre-treatment survey and the reported individual turnout as measured after the treatment has been administered. ${ }^{9}$ Note that in the pretreatment survey, respondents' intention to cast a ballot was measured through a 4-point scale ranging from "very likely" to "not at all likely." In order to achieve comparability with the actual turnout variable (dichotomous), we recoded the turnout intention variable with a value of "1" assigned only to those respondents declaring themselves "very likely" to participate in the forthcoming election, and " 0 " assigned to all others.

The dependent variable measures the VAA's capacity to mobilize those who intend to abstain from the elections but subsequently still vote. Therefore, it is coded " 1 " for all those cases in which the respondent aims to abstain at $t_{-1}$, but then declares having participated in the election $(N=234)$. The variable is coded " 0 " for those for whom the intention to participate was equivalent to the reported behavior after elections (i.e., non-mobilized voters): they either planned to vote and voted eventually $(N=538)$ or they did not plan to vote and did not go to the polls $(N=56)$. There were a few respondents who intended to vote, but subsequently did not. These "demobilized" voters $(N=14)$ are coded " $-1 . "$

Figure 2 compares the proportions of respondents on the dependent variable across treatment/control conditions. Whereas the treatment does not seem to affect demobilized voters in either direction, the figure highlights its strong impact on patterns of acrosscampaign mobilization. A total of $22.6 \%$ of respondents in the control group were mobilized during the campaign (i.e., they went to the polls even though they initially did not plan to). In the treatment group, however, this proportion of mobilized voters is $33.3 \%$ (i.e., it is a proportion that is 10.7 percentage points higher than the proportion of mobilized voters in the control group). This corresponds to a very strong treatment effect, only attributable to VAA exposure. Having taken the VAA treatment thus causes voters to reconsider their pre-campaign preference for abstention. While the campaign has mobilized one out of five Italian voters, this proportion goes up to one out of three in case of those exposed to the VAA. We believe that this is a most important result as it causally and positively links VAA exposure to individual turnout. Also note that the size of the effect $(10.7 \%)$ is very much in line with the individual level results stemming from our analyses based on observational data (see Table 3 ).

Digging deeper, we proceed with a subgroup analysis that allows us to shed further light on what part of the sample was more or less strongly affected by the treatment effect (see Figure 3).The dotted line represents the mean effect (10.7\%) across the sample. Values above the line indicate above-the-mean effect sizes. We find that women and voters with low levels of interest in politics are more strongly mobilized by VAA exposure. However, the strongest effect can be found among the younger generation. Those just entering political life (18 to 24 years old) are twice as strongly affected by VAA exposure and mobilized at the polls. This figure is even higher for the 25- to 34-year-old Italian respondents. In general, it seems as though VAA exposure has a compensating effect on the traditional bias in electoral participation: women, the young, and those who are, from the outset, less interested in politics seem to strongly react to the exposure of this particular type of campaign information - and in a very positive way, bringing their respective probabilities of being mobilized to high levels. Normatively speaking, and while VAA exposure does not seem to significantly affect more or less educated voters, it does incentivize women, the young, and the less interested to get mobilized and therefore to reach more desirable levels of representation. 


\section{Concluding Remarks}

This article contributes to the emerging debate on information and communication technologies (ICTs) and elections, focusing on a new type of interactive online tool: voting advice applications. As VAAs become increasingly important in electoral processes around the world, their mobilizing potential calls for a careful empirical assessment. Our cross-sectional comparative analysis shows that VAA users are systematically more likely to cast their ballot in elections as compared to non-users. Further research, taking into account a larger number of countries-possibly beyond the "traditional" VAA countries - and diverse electoral settings (e.g., first- versus secondorder contexts) is in order if we are to establish more firmly the generalizability of this conclusion. Needless to say, cross-national data availability is a key prerequisite for large-number comparative analyses. With VAAs expanding rapidly beyond Western Europe, however, there are grounds to believe that national election studies worldwide will pay increasing attention to these tools.

As to the results of our experiment, we find further support for the idea that the VAA impact takes place independently of whether voters self-select themselves into using the tool (as is the case in our cross-sectional analysis). The experiment itself contributes to the research on the mobilizing potential of VAAs through an "ideal" design: an experiment on a nationally representative sample of Internet users in the context of a real election. The scattered diffusion of VAAs in the Italian context at the time of our experiment provided the - possibly non-replicable - conditions to test VAA effects in a sort of nationwide laboratory. The choice of Italy as a case study further substantiated previous findings stemming from those countries where effects could be imputed to the widespread diffusion of VAAs (e.g., Gemenis \& Rosema, 2014). In this respect, the pervasive diffusion of VAAs in electoral democracies, in the West and beyond, will in all likelihood push future experimental research to move from the field to the lab. In turn, more refined research designs will help disentangle the causal mechanism behind VAA effects, also looking at other outcomes of interest (e.g., party choice).

Moving to the normative implications of our results, we first find a causal effect of being mobilized due to VAA exposure that is very large, indeed. While the electoral campaign expectedly pushes voters to go to the polls, even if they did not initially plan to do so, the proportion of mobilized voters among VAA users is more than 10 percentage points larger. This is good news for democracy, as it confirms what has been so far more often assumed than measured: exposure to an academically designed, simple, and politically neutral VAA can greatly impact a voter's intention to go to the polls. When focusing on this portion of the electorate that is indeed mobilized due to VAA exposure, we also find a second, normatively most desirable effect of VAA exposure: not only does the latter cause higher mobilization, it does so among groups in the electorate that are prone to electoral abstention: women, the younger, and the less interested in politics. Clearly, when having access to this political navigation aid that a VAA offers its users, some traditionally less electorally participating citizens start to turn out. This, in turn, leads to their better representation in politics. We believe that this result is most encouraging for replicating our experiment in different contexts in order to establish more generalizable insights in this regard. However, for the time being, our results are, in our view, more than encouraging from a normative democratic point of view. 


\section{Acknowledgments}

The authors are indebted to Paolo Bellucci for granting us access to the online panel of the Italian National Election Study and Kristijan Vassil for providing the technological solution implemented in our experimental design. We would also like to thank Lorenzo De Sio and Davide Morisi for their precious help in the conceptual development of the experimental VAA platform and Pellegrino Cammino, Simone Cresti, Alba Cicala, Francesco Visconti for the coding of Italian parties' issue positions. Previous versions of this article have been presented at the 7th ECPR General Conference (Bordeaux, September 2013), the 27th Annual Conference of the Italian Society of Political Science (Florence, September 2013), the EUDO Annual Dissemination Conference (Fiesole, Nobember 2013), the Western Political Science Association Annual Meeting (Las Vegas, April 2015), the Annual Conference of the Italian Society of Political Communication (Salerno, December 2015) and the 2nd Barcelona-Gothenburg Workshop on Experimental Political Science (Barcelona, May 2016). Amongst the large number of people that we would like to thank for their useful comments and suggestions, we will single out R. Micheal Alvarez, James Cross, Russell Dalton, Peter Esaiasson, Bernie Grofman, Hanspeter Kriesi, Andreas Ladner, Ingo Linsemann, Paolo Mancini, Stefan Marschall, Jordi Muñoz, Joelle Pianzola, Martin Rosema, Guido Schwerdt, Rune Slothuus, Paul Sniderman, Maria Laura Sudulich, Michael Tomz and Stefaan Walgrave. Needless to say, all the unavoidable mistakes still present remain entirely ours.

\section{Supplemental Material}

Supplemental data for this article can be accessed on the publisher's website at: http://dx.doi.org/ 10.1080/10584609.2016.1267053.

\section{Notes}

1. A large corpus of the literature in political behavior concentrates on the study of aggregatelevel turnout (for an overview of the most important models and their explanatory power see the meta-analysis by Geys [2006]). In this contribution, however, we are solely focusing on individuallevel turnout.

2. However, one notes that in both the 2006 and 2010 Dutch studies, the "direct" VAA-usage question was asked only to the subset of respondents who declared in a previous question that they "know one or more tests of political preference on the internet." In this analysis, we coded "0" all those who answered negatively to the "filter" question, under the assumption that respondents cannot have made use of something (i.e., the VAA) they are unaware of.

3. Answer options are: "a great deal" (frequency distribution between $2.3 \%$ in 2003 and $4.6 \%$ in $2011)$, "quite a lot" $(5.7 \% \sim 15.7 \%)$, "not very much" $(13.9 \% \sim 22.6 \%)$, and "not at all" $(77.2 \%$ $56.9 \%$ ). In the analysis presented in Table 2, all respondents picking any of the first three answers are coded as VAA users. To test the robustness of our estimates, we tested different recoding strategies. At first, we excluded the respondents picking the "not very much" option from the pool of VAA users. Regression estimates, however, remained virtually identical. We also assessed our results against a highly conservative coding strategy, whereby only those respondents declaring to have followed the campaign on VAAs "quite a lot" were coded as users. In this case, however, the severe underestimation of actual users turned the VAA-usage coefficient insignificant in each and every model.

4. It is well-known that national election studies suffer from a severe over-reporting of electoral turnout levels due to social desirability bias (Karp \& Brockington, 2005). Inevitably, this has potential implications for our own analysis. On the one hand, one could charge that this bias leads 
to overestimation of the mobilization effect of the VAA, insofar as abstainers are strongly underrepresented in the sample. On the other hand, however, one could argue that overestimation of turnout levels leads to underestimation of the impact of VAA usage due to ceiling effects - if almost all study respondents are voters, there is not much room left for further increase in levels of electoral participation. As the data at hand do not allow for an empirical assessment of the actual size of these biases, we proceed with our analysis under the assumption that they are by and large equivalent, thus potentially canceling each other out.

5. Indeed, all parties that eventually polled at least $0.5 \%$ of the votes at the national level (and eventually gained representation in the parliament) were included in the VAA platform.

6. The so-called "Manhattan" (or city-block) distance expresses how close two respective points are from one another in an n-dimensional space. With a 5-point response scale, the maximum possible distance between a party and a user on a given statement equals four points. With a questionnaire of 30 statements, the maximum distance is 120 points, whereas the minimum distance is zero points. We rescaled these values so that maximum party/user distance equals to $0 \%$ on the match-list and minimum distance equals to $100 \%$.

7. The main drawback of CAWI technology lies in the slightly biased demographics of those who tend to respond to online questionnaire invitations. Indeed, youngsters were slightly overrepresented in our sample (mean age is 45.5 as compared to the 49.4 in the CATI postelectoral survey fielded simultaneously by ITANES) and so were respondents with high educational level (university graduates are $23.4 \%$ of the sample as opposed to $12.9 \%$ among CATI respondents).

8. We performed a balance test of treatment assignment based on a parsimonious set of typical predictors of VAA usage (i.e., age, gender, educational level, and political interest). The results show that the sample is well-balanced: none of the predictors discriminates the two groups in a statistically significant way (detailed model estimation is presented in Appendix C). This confirms that the random assignment was performed correctly, so it is possible not to include control variables when comparing treatment and control groups.

9. Due to missing values (i.e., don't know, no answer) on the turnout variable in either wave, 46 respondents have been excluded from the analysis.

\section{References}

Alvarez, M., Levin, I., Trechsel, A., \& Vassil, K. (2014). Voting advice applications: How useful and for whom? Journal of Information Technology \& Politics, 11, 82-101. doi:10.1080/ 19331681.2013.873361

Angrist, Joshua David, Jörn-Steffen Pischke, and Jörn-Steffen Pischke. Mostly harmless econometrics: an empiricist's companion. Vol. 1. Princeton: Princeton University Press, 2009.

Barisione, M., Catellani, P., \& Garzia, D. (2013). Allaricerca di un leader [Looking for a leader]. In ITANES (Ed.), Il Voto Amaro. Bologna, Italy: Il Mulino.

Bond, R., Fariss, C., Jones, J., Kramer, A., Marlow, C., Settle, J., \& Fowler, J. (2012). A 61-millionperson experiment in social influence and political mobilization. Nature, 489, 295-298. doi:10.1038/nature11421

Boulianne, S. (2009). Does Internet use affect engagement? A meta-analysis of research. Political Communication, 26, 193-211. doi:10.1080/10584600902854363

Carmines, E., \& Huckfeldt, R. (1996). Political behavior: An overview. In R. Goodin \& H.-D. Klingemann (Eds.), A new handbook of political science (pp. 223-254). Oxford, UK: Oxford University Press.

Chadwick, A., \& Howard, P. (Eds.). (2009). Routledge handbook of Internet politics. Abingdon, UK: Routledge.

Delli Carpini, M., \& Keeter, S. (1996). What Americans don't know about politics and why it matters. New Haven, CT: Yale University Press.

Dinas, E., Trechsel, A., \& Vassil, K. (2014). A look into the mirror: Preferences, representation and electoral participation. Electoral Studies, 36, 290-297. doi:10.1016/j.electstud.2014.04.011 
Downs, A. (1957). An economic theory of political action in a democracy. The Journal of Political Economy, 65, 135-150. doi:10.1086/257897

Enyedi, Z. (2015). The influence of voting advice applications on preferences, loyalties and turnout: An experimental study. Political Studies. Advance online publication. doi:10.1111/ $1467-9248.12213$

Fivaz, J., \& Nadig, G. (2010). Impact of voting advice applications (VAAs) on voter turnout and their potential use for civic education. Policy \& Internet, 2, 167-200. doi:10.2202/ 1944-2866.1025

Garzia, D., De Angelis, A., \& Pianzola, J. (2014). The impact of voting advice applications on electoral participation. In D. Garzia \& S. Marschall (Eds.), Matching voters with parties and candidates. Voting 570 advice applications in a comparative perspective. Colchester, UK: ECPR Press.

Garzia, D., Trechsel, A., Vassil, K., \& Dinas, E. (2014). Indirect campaigning: Past, present and future of voting advice applications. In B. Grofman, A. Trechsel, \& M. Franklin (Eds.), The Internet and democracy in global perspective: Voters, candidates, parties, and social movements. New York, NY: Springer.

Gemenis, K., \& Rosema, M. (2014). Voting advice applications and electoral turnout. Electoral Studies, 36, 281-289. doi:10.1016/j.electstud.2014.06.010

Geys, B. (2006). Explaining voter turnout: A review of aggregate-level research. Electoral Studies, 25, 637-663. doi:10.1016/j.electstud.2005.09.002

Hirzalla, F., Van Zoonen, L., \& De Ridder, J. (2010). Internet use and political participation: Reflections on the mobilization/normalization controversy. The Information Society, 27, 1-15. doi:10.1080/01972243.2011.534360

Kamoen, N., Holleman, B., Krouwel, A., Van De Pol, J., \& De Vreese, C. (2015). The effect of voting advice applications on political knowledge and vote choice. Irish Political Studies, 30, 595-618. doi:10.1080/07907184.2015.1099096

Karp, J., \& Brockington, D. (2005). Social desirability and response validity: A comparative analysis of overreporting voter turnout in five countries. Journal of Politics, 67, 825-840. doi:10.1111/ j.1468-2508.2005.00341.x

Ladner, A. (2012, Voting advice applications: Impact on voting decisions in the 2011 Swiss national elections. Paper presented at the PSA Annual Conference, Belfast, UK.

Ladner, A., Fivaz, J., \& Nadig, G. (2009). Voting assistance applications as tools to increase political participation and improve civic education. In M. Print \& H. Milner (Eds.), Civic education and youth political participation (pp. 43-60). Rotterdam, Netherlands; Boston, MA, USA; Taipei, Taiwan: Sense.

Ladner, A., \& Pianzola, J. (2010). Do voting advice applications have an effect on electoral participation and voter turnout? Evidence from the 2007 Swiss federal elections. In E. Tambouris, A. Macintosh, \& O. Glassey (Eds.), Electronic participation (pp. 211-224). Berlin, Germany: Springer.

Lassen, D. (2005). The effect of information on voter turnout: Evidence from a natural experiment. American Journal of Political Science, 49, 103-118. doi:10.1111/ajps.2005.49.issue-1

Mahéo, V.-A. (2014). Can voting aid applications mobilize disadvantaged citizens? A field experiment in the 2014 Quebec election. Paper presented at the MPSA Annual Conference, Chicago, IL.

Marschall, S. (2005). Idee und Wirkung des Wahl-O-Mat [Ideas and Effects of Wahl-O-Mat]. Aus Politik Und Zeitgeschichte, 55, 41-46.

Marschall, S. (2014). Profiling users. In D. Garzia \& S. Marschall (Eds.), Matching voters with parties and candidates. Voting 570 advice applications in a comparative perspective. Colchester, UK: ECPR Press.

Marschall, S., \& Garzia, D. (2014). Voting advice applications in a comparative perspective: An introduction. In D. Garzia \& S. Marschall (Eds.), Matching voters with parties and candidates. Voting 570 advice applications in a comparative perspective. Colchester, UK: ECPR Press. 
Marschall, S., \& Schmidt, C. (2010). The impact of voting indicators: The case of the German WahlO-Mat. In L. Cedroni \& D. Garzia (Eds.), Voting advice applications in Europe (pp. 61-86). Napoli, Italy: Civis.

Marschall, S., \& Schultze, M. (2012). Voting advice applications and their effect on voter turnout: The case of the German Wahl-O-Mat. International Journal of Electronic Governance, 5, 349 366. doi:10.1504/IJEG.2012.051314

Norris, P. (2000). A virtuous circle: Political communication in post-industrial societies. Cambridge, UK: Cambridge University Press.

Palfrey, T., \& Poole, K. (1987). The relationship between information, ideology, and voting behavior. American Journal of Political Science, 31, 511-530. doi:10.2307/2111281

Pianzola, J. (2014). Mirror me: The effect of the voting advice application smartvote on voting preferences and behavior of Swiss voters (NCCR Working Paper no. 73). University of Zurich, Zurich.

Popkin, S. (1991). The reasoning voter: Communication and persuasion in presidential elections. Chicago, IL: University of Chicago Press.

Ruusuvirta, O. (2010). Much ado about nothing? Online voting advice applications in Finland. In L. Cedroni \& D. Garzia (Eds.), Voting advice applications in Europe (pp. 47-77). Napoli, Italy: Civis.

Schultze, M. (2014). Effects of voting advice applications (VAAs) on political knowledge about party positions. Policy \& Internet, 6, 46-68. doi:10.1002/1944-2866.POI352

Smets, K., \& Van Ham, C. (2013). The embarrassment of riches? A meta-analysis of individual-level research on voter turnout. Electoral Studies, 32, 344-359. doi:10.1016/j.electstud.2012.12.006

Tolbert, C., \& McNeal, R. (2003). Unraveling the effects of the Internet on political participation? Political Research Quarterly, 56, 175-185. doi:10.1177/106591290305600206

Vassil, K. (2012). Voting smarter? The impact of voting advice applications on political behavior (Unpublished doctoral dissertation). Fiesole, Italy: European University Institute..

Verba, S., Schlozman, K., \& Brady, H. (1995). Voice and equality: Civic voluntarism in American politics. Cambridge, MA: Harvard University Press.

Walgrave, S., Van Aelst, P., \& Nuytemans, M. (2008). "Do the vote test": The electoral effects of a popular vote advice application at the 2004 Belgian elections. Acta Politica, 43, 50-70. doi:10.1057/palgrave.ap.5500209. 